\title{
Predictive Performance of SYNTAX Score II in Patients With Left Main and Multivessel Coronary Artery Disease
}

\author{
- Analysis of CREDO-Kyoto Registry -
}

\author{
Carlos M. Campos, MD; David van Klaveren; Javaid Iqbal, MD, PhD; Yoshinobu Onuma, MD, PhD; \\ Yao-Jun Zhang, MD, PhD; Hector M. Garcia-Garcia, MD, PhD; Marie-Angele Morel, BSc; \\ Vasim Farooq, MD, PhD; Hiroki Shiomi, MD; Yutaka Furukawa, MD; Yoshihisa Nakagawa, MD; \\ Kazushige Kadota, MD; Pedro A. Lemos, MD, PhD; Takeshi Kimura, MD; \\ Ewout W. Steyerberg, PhD; Patrick W. Serruys, MD, PhD
}

\begin{abstract}
Background: SYNTAX score II (SSII) provides individualized estimates of 4-year mortality after coronary artery bypass grafting $(\mathrm{CABG})$ and percutaneous coronary intervention $(\mathrm{PCl})$ in order to facilitate decision-making between these revascularization methods. The purpose of the present study was to assess SSII in a real-world multicenter registry with distinct regional and epidemiological characteristics.
\end{abstract}

\begin{abstract}
Methods and Results: Long-term mortality was analyzed in 3,896 patients undergoing $\mathrm{PCI}(\mathrm{n}=2,190)$ or CABG $(n=1,796)$ from the Coronary REvascularization Demonstrating Outcome Study in Kyoto (CREDO-Kyoto) PCI/CABG registry cohort-2. SSII discriminated well in both CABG and PCI patient groups (concordance index [c-index], 0.70; 95\% Cl: 0.68-0.72; and 0.75, 95\% Cl: 0.72-0.78) surpassing anatomical SYNTAX score (SS; c-index, 0.50; 95\% Cl: $0.47-0.53$; and $0.59,95 \% \mathrm{Cl}: 0.57-0.61)$. SSII had the best discriminative ability to separate low-, medium- and high-risk tertiles, and calibration plots showed good predictive performance for CABG and PCI groups. Use of anatomical SS as a reference improved the overall reclassification provided by SSII, with a net reclassification index of $0.5(\mathrm{P}<0.01)$.
\end{abstract}

Conclusions: SSII has robust prognostic accuracy, both in CABG and in PCI patient groups and, compared with the anatomical SS alone, was more accurate in stratifying patients for late mortality in a real-world complex coronary artery disease Eastern population. (Circ $J$ 2014; 78: 1942-1949)

Key Words: Coronary artery bypass grafting; Percutaneous coronary intervention; Risk stratification; SYNTAX score; SYNTAX score II

$\mathbf{P}$ ercutaneous coronary intervention (PCI), until recently, has been considered a class III indication (ie, potentially harmful) for patients with unprotected left main (ULMCA) and 3-vessel coronary artery disease (CAD). ${ }^{1,2}$ Coronary artery bypass grafting $(\mathrm{CABG})$ has been the standard treatment for these patients with complex CAD for more than 50 years. Over the last decade, PCI has undergone a number of technical and technological advancements and hence has challenged the superiority of CABG. ${ }^{3}$ Consequently, every ad- vance in PCI technology has been scrutinized and compared against $\mathrm{CABG}$, generating debate as to whether a patient should be referred to $\mathrm{CABG}$ or PCI, with advantages for one or the other depending on context. ${ }^{4-10}$ Therefore, the accurate risk estimation of multivessel CAD remains a fundamental step in the decision-making process. ${ }^{11}$

\section{Editorial p1832}

Received March 7, 2014; revised manuscript received May 1, 2014; accepted May 14, 2014; released online July 7, 2014 Time for primary review: 20 days

Department of Interventional Cardiology (C.M.C., J.I., Y.O., Y.-J.Z., H.M.G.-G., M.-A.M., V.F., P.W.S.), Department of Public Health (D.v.K., E.W.S.), Erasmus Medical Centre-University Medical Centre Rotterdam, Rotterdam, The Netherlands; Heart Institute (InCor), University of São Paulo Medical School, Sao Paulo (C.M.C., P.A.L.), Brazil; Department of Cardiovascular Medicine, Graduate School of Medicine, Kyoto University, Kyoto (H.S., T.K.); Department of Cardiovascular Medicine, Kobe City Medical Center General Hospital, Kobe (Y.F.); Division of Cardiology, Tenri Hospital, Tenri (Y.N.); Division of Cardiology, Kurashiki Central Hospital, Kurashiki (K.K.), Japan; and Department of Cardiology, Imperial College London, London (P.W.S.), UK

Mailing address: Patrick W. Serruys, MD, PhD, Professor of Medicine, Head of Interventional Cardiology Department, Erasmus MC, 'sGravendijkwal 230, 3015 CE Rotterdam, The Netherlands. E-mail: p.w.j.c.serruys@erasmusmc.nl

ISSN-1346-9843 doi:10.1253/circj.CJ-14-0204

All rights are reserved to the Japanese Circulation Society. For permissions, please e-mail: cj@j-circ.or.jp 


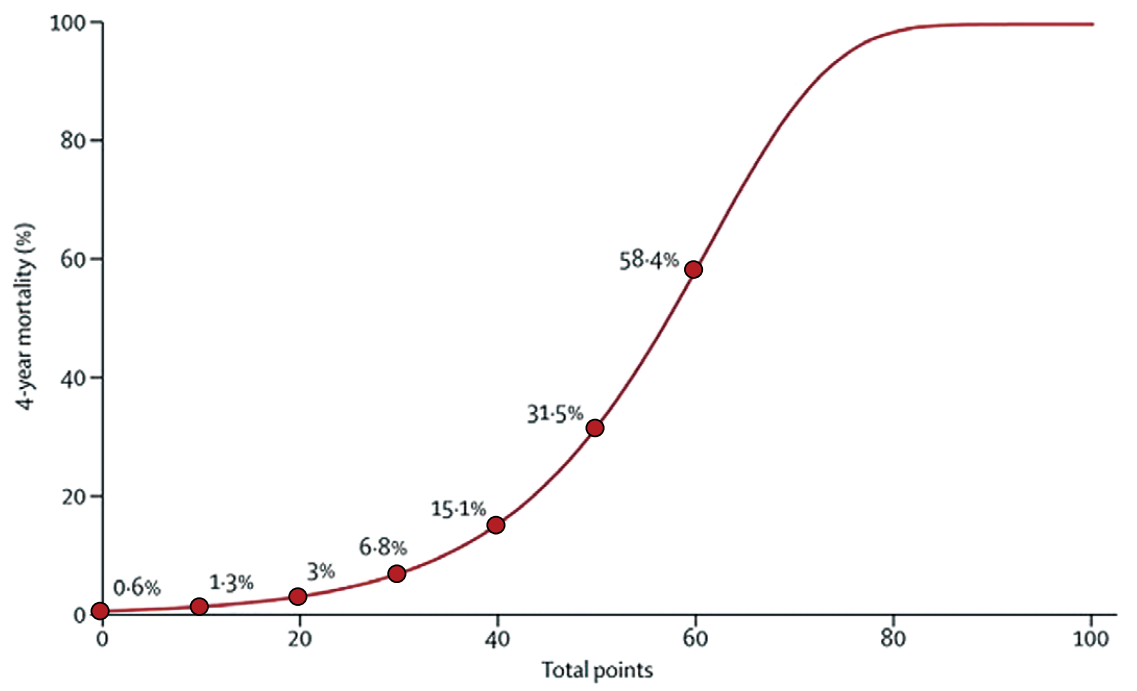

CABG

024681012141618202224262830

Points

SYNTAX score 1

$1^{1}$

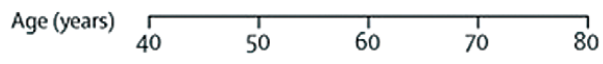

$\mathrm{CrCl}(\mathrm{mL} / \mathrm{min}) \stackrel{1}{90 \quad 60 \quad 30}$

LVEF (\%)

Left main

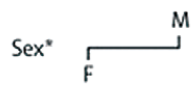

COPD

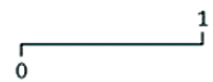

PVD

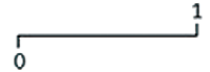

$\mathrm{PCI}$

024681012141618202224262830 $\begin{array}{lrrrrrr}0 & 10 & 20 & 30 & 40 & 50 & 60\end{array}$

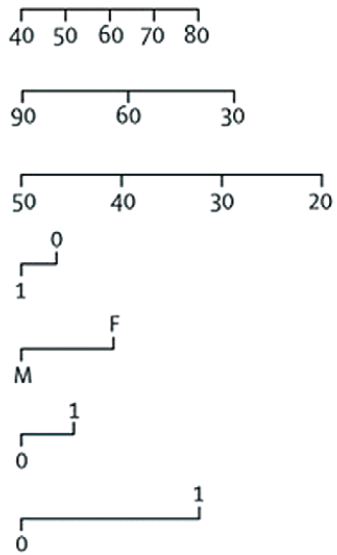

Figure 1. SYNTAX score II nomogram for bedside application. Total number of points for 8 factors can be used to accurately predict 4-year mortality for the individual patient preparing to undergo $\mathrm{CABG}$ or PCl. 3VD, 3-vessel disease; CABG, coronary artery bypass grafting; COPD, chronic obstructive pulmonary disease; $\mathrm{CrCl}$, creatinine clearance; left main, unprotected left main coronary artery disease; LVEF, left ventricular ejection fraction; $\mathrm{PCl}$, percutaneous coronary intervention; PVD, peripheral vascular disease. (Adapted with permission from Faroog $\mathrm{V}$, et al. ${ }^{14}$ )
Presently, for patients with ULMCA or complex CAD, the prevailing guidelines recommend a multidisciplinary approach referred to as the heart team. ${ }^{12,13}$ These guidelines also advise the heart team to use synergy between PCI with taxus and cardiac surgery (SYNTAX) score alone or combined with the Society of Thoracic Surgeons (STS) score as a tool to make an objective risk stratification. ${ }^{12,13}$ The SYNTAX score II (SSII) has been recently developed by applying a Cox proportional hazards model to the results of the SYNTAX trial, obtaining a combination of clinical and anatomical predictors. ${ }^{9,14}$ Given that the SSII has been derived from an all-comers randomized trial of PCI vs. CABG, it has the potential to assess individual risk estimation between these revascularization strategies and facilitate multidisciplinary decision-making.

SSII has been shown to provide reliable predictions of 4-year mortality for complex CAD in an external validation of the Drug Eluting stent for LefT main coronary Artery disease (DELTA) registry. ${ }^{14,15}$ The DELTA registry consisted of predominantly Western patients with ULMCA disease. In patients with 3-vessel disease and no left main involvement, however,
SYNTAX score (SS) would represent more complex downstream coronary anatomical disease. This may be a signal of a more adverse risk profile, in patients who have evidence of systemic atherosclerosis and therefore are at greater longerterm cardiovascular risk. ${ }^{16}$ This score has not been assessed in an Eastern population with complex 3-vessel CAD.

The purpose of the present study was therefore to assess SSII in patients with 3-vessel and/or ULMCA disease in a real-world multicenter registry with distinct regional and epidemiological characteristics.

\section{Methods}

\section{Subjects}

The Coronary REvascularization Demonstrating Outcome Study in Kyoto (CREDO-Kyoto) PCI/CABG registry cohort-2 has been previously described in detail. ${ }^{17}$ Briefly, this was a physician-initiated non-industry-sponsored multicenter registry enrolling consecutive patients undergoing first coronary revascularization among 26 centers in Japan between January 2005 


\begin{tabular}{lccr}
\hline Table 1. Subject Baseline Characteristics & & & \\
Clinical caracteristics & $\mathbf{P C l}(\mathbf{n = 2 , 1 9 0 )}$ & $\mathbf{C A B G}(\mathbf{n = 1 , 7 9 6 )}$ & P-value \\
Age (years) & & & \\
Male & $71(63-77)$ & $70(63-75)$ & $<0.01$ \\
BMI & $1,554(71)$ & $1,336(74.4)$ & 0.02 \\
Diabetes & $23.7(21.5-25.8)$ & $23.3(21.1-25.8)$ & $<0.01$ \\
On insulin therapy & $1,066(48.7)$ & $935(52.1)$ & 0.03 \\
Hypertension & $287(13.1)$ & $309(17.2)$ & $<0.01$ \\
Current smoking & $1,907(87.1)$ & $1,514(84.3)$ & 0.01 \\
Heart failure & $541(24.7)$ & $437(24.3)$ & 0.79 \\
Prior MI & $454(20.7)$ & $387(21.5)$ & 0.53 \\
Prior symptomatic stroke & $415(18.9)$ & $396(22)$ & 0.02 \\
Hemodialysis & $346(15.8)$ & $248(13.8)$ & 0.08 \\
COPD & $124(5.7)$ & $119(6.6)$ & 0.21 \\
PVD & $70(3.2)$ & $60(3.3)$ & 1 \\
Ejection fraction (\%) & $227(12.6)$ & $256(11.7)$ & 0.36 \\
Creatinine clearance (mg/dl) & $60(50-67)$ & $60(49-68)$ & 0.85 \\
Procedural characteristics & $61.7(44.2-80.9)$ & $61.4(43.7-78.9)$ & 0.22 \\
CAD extension & & & $<0.01$ \\
3-vessel disease & & & $<0.01$ \\
LM isolated & $1,825(83.3)$ & $1,156(64.4)$ & \\
LM and 1-vessel disease & $57(3.2)$ & $31(1.4)$ & $108(6)$ \\
LM and 2-vessel disease & $89(4.1)$ & $182(10.1)$ & $293(16.3)$ \\
LM and 3-vessel disease & $132(6)$ & $29(23-37)$ & \\
SYNTAX score & $113(5.2)$ & & \\
\hline
\end{tabular}

Data given as median (IQR) or $n(\%)$.

$\mathrm{BMI}$, body mass index; $\mathrm{CABG}$, coronary artery bypass grafting; $\mathrm{CAD}$, coronary artery disease; COPD, chronic obstructive pulmonary disease; LM, left main; MI, myocardial infarction; PCI, percutaneous coronary intervention; PVD, peripheral vascular disease.

and December 2007. The relevant ethics committees in all participating centers approved the research protocol. Because of retrospective enrolment, written informed consent from the patients was waived, excluding those patients who refused participation in the study when contacted for follow-up.

Among 15,939 patients enrolled in the registry, 3,986 participants had 3-vessel and/or ULMCA and were included in current analyses.

\section{SSII}

The SSII has been described in detail previously. ${ }^{14}$ Briefly, SSII uses the 2 anatomical variables (anatomical SS and ULMCA disease) and 6 clinical variables (age, creatinine clearance, left ventricular ejection fraction [LVEF], sex, chronic obstructive pulmonary disease, and peripheral vascular disease) to predict 4-year mortality after revascularization with CABG or PCI.

For the present study, SSII was calculated using a nomogram, with scores assigned for the presence and magnitude of each predictor directly based on the Cox proportional hazards model coefficients (Figure 1), generating different scores for PCI and CABG. ${ }^{14}$ The 4-year mortality estimates were obtained in accordance with the revascularization procedure that each patient underwent: PCI or CABG.

\section{Statistical Analysis}

Categorical variables are presented as numbers and percentages and were compared using the chi-squared test. Continuous variables are expressed as mean \pm SD or median with interquartile range (IQR), and were compared using Student's t-test or Wilcoxon rank-sum test based on their distributions.

SSII predictor data were all present in at least $90 \%$ of the patients. Multiple imputation (5×) of missing data was undertaken using an imputation strategy that takes into account the correlation between all potential predictors. To obtain 4-year mortality predictions based on anatomical SS alone, Cox logistic regression analysis was used with anatomical SS as a sole linear predictor.

SSII for PCI (in patients undergoing PCI) and for CABG (in patients undergoing $\mathrm{CABG}$ ) was evaluated using 4 metrics: c-statistics; calibration plots; reclassification tables; and net reclassification index (NRI). Outcome was analyzed using Kaplan-Meier curves with a 4-year time horizon. Discrimination was studied with the concordance index (c-index) $.^{18} \mathrm{Cal}-$ ibration was assessed by plotting the observed 4-year mortality by quintiles of the predicted 4 -year mortality. ${ }^{19}$ Comparison between the anatomical and II SYNTAX scores was further quantified using a reclassification table and its NRI.20,21 The NRI uses reclassification tables constructed separately for participants with and without events, and quantifies the correct movement in categories: upwards for events and downwards for non-events as follows: NRI=([percentage of events moved to higher risk category in event group]-[percentage of events moved to lower risk category in event group])-([percentage of non-events moved to higher risk category in non-event group][percentage of non-events moved to lower risk category in nonevent group]). Given that not all persons had follow-up completed to 4 years, the present reclassification was based on the expected number of case and control patients calculated using the Kaplan-Meier estimator. ${ }^{21}$ All statistical analysis was done 


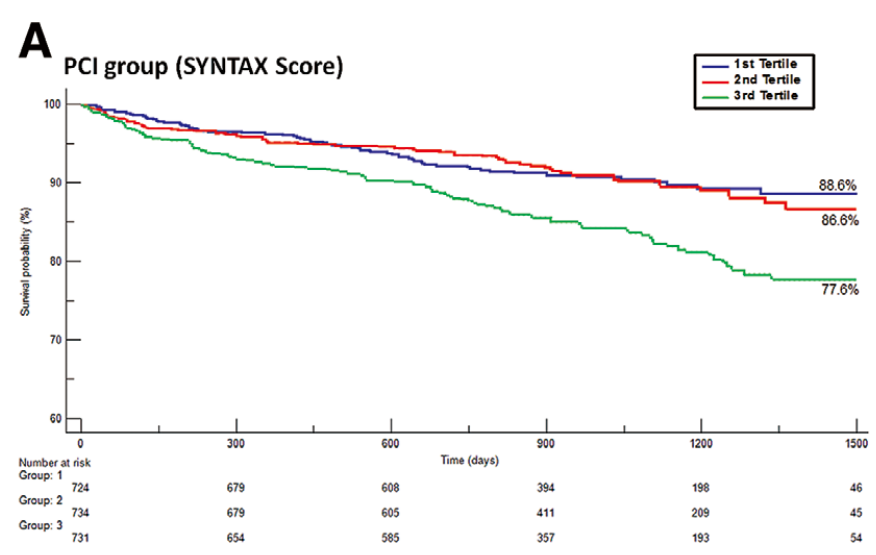

\section{B}

PCl group (SYNTAX Score II)

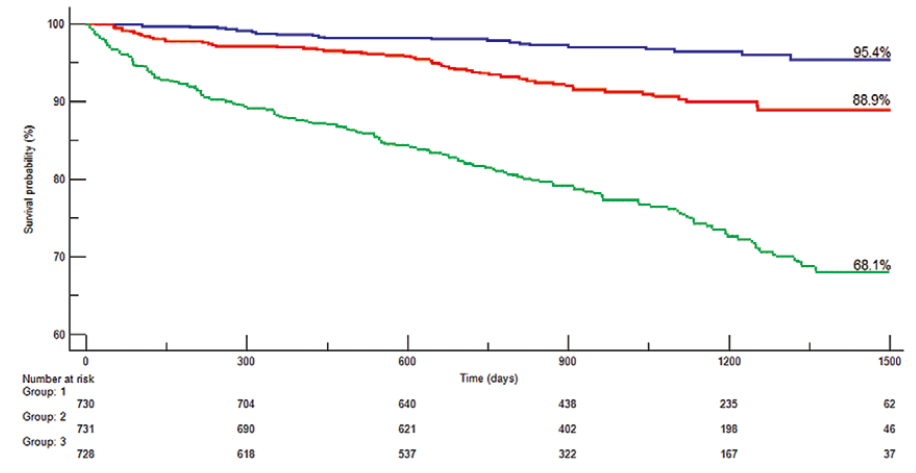

\section{C}

CABG group (SYNTAX Score)

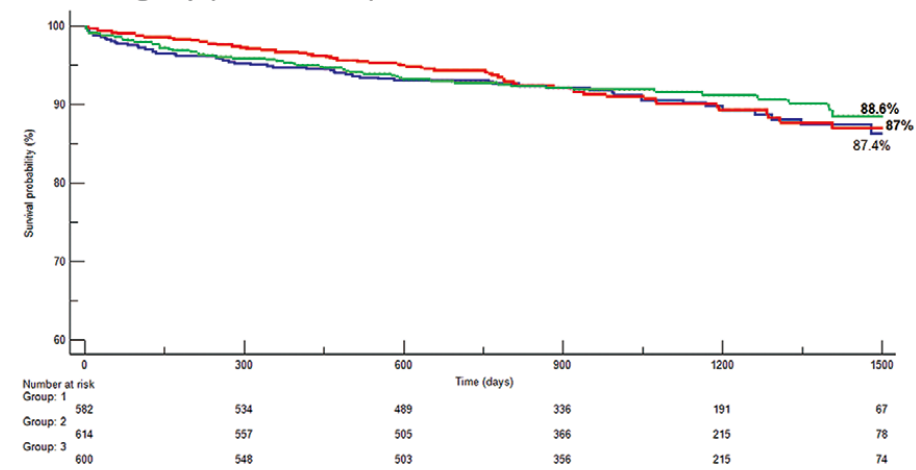

\section{D}

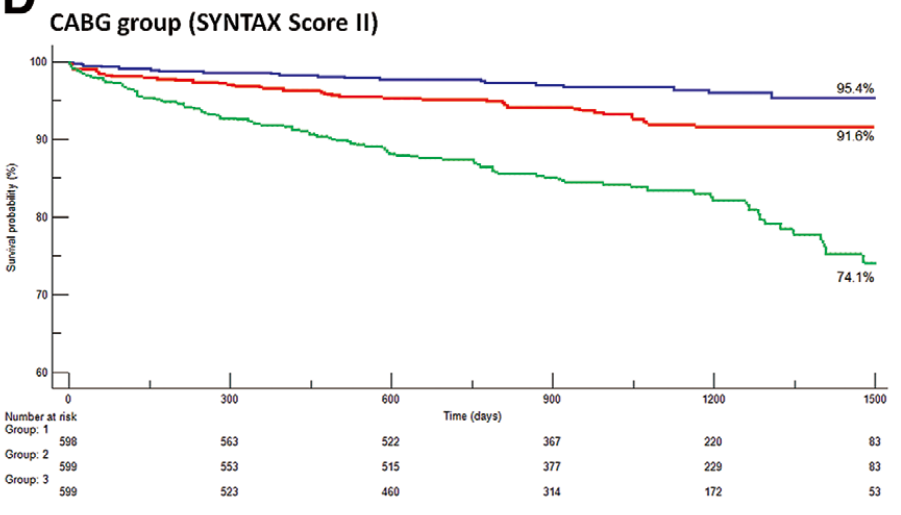

Figure 2. Kaplan-Meier curves for tertiles of anatomical SYNTAX score and SYNTAX score II for the percutaneous coronary intervention $(\mathrm{PCl})$ and coronary artery bypass grafting (CABG) groups. 


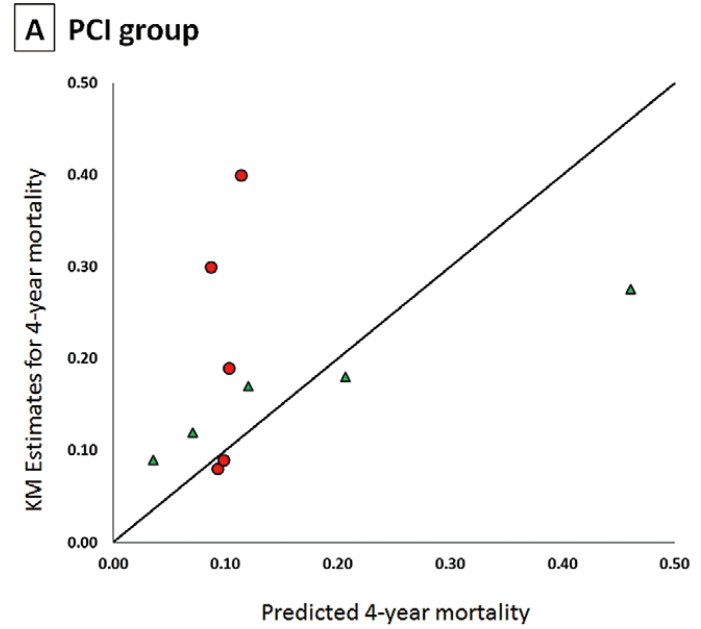

B CABG group

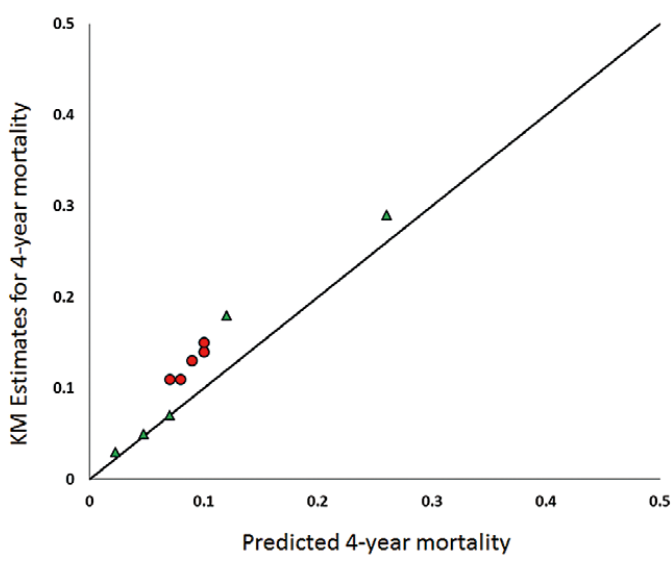

Figure 3. Calibration plots comparing (red circles) anatomical SYNTAX score against (green triangles) SYNTAX score II for the percutaneous coronary intervention $(\mathrm{PCI})$ and coronary artery bypass grafting (CABG) groups.

\begin{tabular}{|c|c|c|c|c|}
\hline \multirow{2}{*}{$\begin{array}{l}\text { PCI and CABG cohorts Predicted mortality by SS } \\
0-5 \%\end{array}$} & \multicolumn{4}{|c|}{ Predicted mortality by SSII } \\
\hline & $<5 \%$ & $>5-10 \%$ & $>10 \%$ & Total \\
\hline Persons included & $0^{*}$ & 0 & 0 & 0 \\
\hline Death & $0^{*}$ & 0 & 0 & 0 \\
\hline Survival & $0^{*}$ & 0 & 0 & 0 \\
\hline 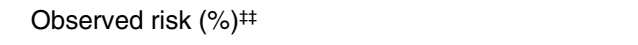 & $0^{*}$ & 0 & 0 & 0 \\
\hline \multicolumn{5}{|l|}{$>5-10 \%$} \\
\hline Persons included & 778 & $678^{*}$ & 1,128 & 2,584 \\
\hline Death & $28.0^{\dagger+}$ & $57.0^{*}$ & $270.7^{\dagger}$ & 355.7 \\
\hline Survival & $750.0 \$$ & $621.0^{*}$ & $857.3^{\star *}$ & $2,228.3$ \\
\hline Observed risk $(\%)^{\ddagger \ddagger}$ & 3.6 & $8.4^{*}$ & 24.0 & 13.8 \\
\hline \multicolumn{5}{|l|}{$>10 \%$} \\
\hline Persons included & 359 & 365 & $678^{*}$ & 1,402 \\
\hline Death & $19.0^{\dagger+}$ & $29.2^{t \dagger}$ & $183.7^{\star}$ & 232.0 \\
\hline Survival & $340.0 \$$ & $335.8 \S$ & $494.3^{*}$ & $1,170.0$ \\
\hline Observed risk $(\%)^{\ddagger \ddagger}$ & 5.3 & 8.0 & $27.1^{*}$ & 16.5 \\
\hline \multicolumn{5}{|l|}{ Total } \\
\hline Persons included & 1,137 & 1,043 & 1,806 & 3,986 \\
\hline Death & 47.0 & 86.2 & 454.5 & 587.6 \\
\hline Survival & $1,090.0$ & 956.8 & $1,351.5$ & $3,398.4$ \\
\hline Observed risk $(\%)^{\ddagger \ddagger}$ & 4.1 & 8.3 & 25.2 & 14.7 \\
\hline
\end{tabular}

*Patients classified as having the same risk by both scores; ${ }^{*}$ patients classified as having higher risk by SSII who survived; †patients classified as having higher risk by SSII who died; ${ }^{\dagger}$ patients classified as having lower risk by SSII who died; spatients classified as having lower risk by SSII who died survived.

fFor patients who died the SSII reclassification improved by 33\% whereas in non-event patients the reclassification improved by $16.7 \%$. The net reclassification index was $0.5(P<0.01)$. ${ }^{\ddagger}$ Estimated from the Kaplan-Meier curve using observations in each cell.

SS, SYNTAX score; SSII, SYNTAX score II. Other abbreviations as in Table 1.

using IBM SPSS Statistics for Windows, version 21.0 (IBM, Armonk, NY, USA).

\section{Results}

Patient Characteristics

Out of 3,986 patients included in the current study, 2,190 patients received PCI and 1,796 patients underwent CABG. 
Baseline characteristics of these patients are listed in Table $\mathbf{1 .}$ Patients in the PCI group were older, and more often had hypertension, while patients in the CABG group more often had smaller body mass index, diabetes and prior myocardial infarction. Participants treated with CABG had more complex anatomical characteristics and a higher prevalence of associated ULMCA-triple vessel disease and higher anatomical SS. Overall Kaplan-Meier estimated mortality at 4-year follow-up was $14.7 \%$ (15.9\% for PCI and $12.6 \%$ for CABG).

\section{Predictive Performance of SSII}

Discrimination The c-index of SSII was 0.70 (95\% CI: 0.68-0.72) in the CABG group and 0.75 (95\% CI: 0.72-078) in the PCI group. On comparison of discrimination, anatomical SYNTAX showed a significant improvement for CABG and PCI groups (c-index, 0.50; 95\% CI: $0.47-0.53$ and 0.59 , 95\% CI: 0.57-0.61; respectively). Additionally, the SSII model was able to separate low-, medium- and high-risk tertiles better than anatomical SS for both groups (Figure 2).

Calibration The validation plots (Figure 3 ) of SSII indicated a reasonably good agreement between the observed and predicted risks for both the CABG and PCI groups. The anatomical SS showed disparity between predicted and observed mortality.

Reclassification Reclassification for all patients (both PCI and CABG patient groups), with and without events is summarized in Table 2. SSII showed a significant improvement in risk stratification (NRI, $0.5 ; \mathrm{P}<0.01$ ). This was also observed when analyzing the PCI and CABG groups separately (Table S1).

\section{Discussion}

In this study, SSII was assessed in a large all-comers registry of Eastern patients with predominantly high-risk CAD. The findings can be summarized as follows: (1) SSII showed agreement between observed outcomes and predictions; (2) the metrics used showed similar risk stratification for both treatment cohorts (PCI and CABG); and (3) SSII substantially improved the predictive accuracy of long-term mortality predictions if compared with the anatomical SS alone.

SSII was developed from comparison between CABG and PCI in the SYNTAX trial. ${ }^{14}$ Its concept permits the composition of 1 single score to predict - based on randomized data - mortality if a patient is assigned to either CABG or PCI. Indeed, in the present study, SSII had similar and consistent predictive performance for both revascularization strategies in a real world population. In contrast, the current guidelines advise the heart team to use the anatomical SS alone or combined with the STS score as a tool to make objective risk stratification in the decision-making process between CABG and PCI. ${ }^{12,13}$ This concept, however, does not allow unified risk assessment. The anatomical SS has prognostic relevance only for patients assigned to PCI.9,19,22 Despite the fact that the STS score has been widely used for risk stratification in cardiac surgery, ${ }^{23-25}$ it was not formally validated as a predictive tool for PCI.

The metrics used to perform the present analysis reinforce the importance of comprehensive assessment with a combination of angiographic and key clinical characteristics for patients with complex CAD. ${ }^{26}$ SSII had a significantly higher accuracy compared to anatomical SS for all-cause death measured by the c-statistic. It has been argued, however, that c-statistic is insensitive to systematic errors in calibration such as differences in average outcome. ${ }^{20,27}$ Therefore, we studied calibration using a graphical representation where predicted risk matched observed risk. In this comparison the SSII also had a more re- fined pattern (Figure 2). Indeed, a better discriminating model has more spread between quintiles of predicted risk than a poorly discriminating model. ${ }^{20,28}$

Additionally, it is important for risk prediction as to whether a model can accurately stratify individuals into higher or lower risk categories. Therefore, we used the methodology described previously, ${ }^{20,21}$ which balances the reclassification of a new score, subtracting, from a better risk grouping, a penalty if it lowers the estimated risk category of a patient with event or raises the estimated risk category of a patient without event. The overall NRI of $0.5(\mathrm{P}<0.01)$ indicates that $50 \%$ of patients had a net better classification for higher and lower risk categories using the SSII vs. the anatomical SS. Also, when reclassified separately for type of revascularization - PCI or CABG - the reclassification of SSII was more accurate, indicating its potential as an integrated prediction tool (Table S1). Grouping patients in tertiles according to SSII, a separation of the Kaplan-Meier curves for the occurrence of deaths is evident (Figure 2). The same approach for anatomical SS showed a poor risk stratification (Figure 2).

Previously, SSII was predominantly evaluated in Western patients. ${ }^{15}$ Therefore, doubts may have existed over the utility of this tool in other populations. The present analysis confirms the potential to apply this model globally, given that we have now validated it in a population with unique epidemiological characteristics. Japan has the longest life expectancy at birth worldwide and a substantially lower proportion of mortality from cardiovascular diseases, compared with Western countries. ${ }^{29,30}$ Despite recent changes in the lifestyle and dietary habits of Japanese people, the incidence of myocardial infarction in Japan is still much lower than in other industrialized countries. ${ }^{31,32}$ Furthermore, even after revascularization - by either PCI or CABG - Japanese patients have been shown to have better long-term outcomes than US patients ${ }^{33}$ and, regarding PCI, a significantly lower definite stent thrombosis than in Western countries. ${ }^{34}$ All the aforementioned reasons could suggest that a score developed and validated mainly in Western populations may be less appropriate for global use. In the present cohort SSII discriminated well in both CABG and PCI patient groups (c-index, $0.70 ; 95 \% \mathrm{CI}: 0.68-0.72$ and $0.75,95 \% \mathrm{CI}$ : $0.72-0.78$, respectively), a performance similar to its internal (c-index, 0.72) and external validations (DELTA registry; cindex, 0.71) in mainly Western patients.

Once more, the SSII predictions were consistent despite the fact that it does not include in its model diabetes mellitus. This could be questioned as a paradox because in the exclusively diabetic patients of the FREEDOM trial, CABG was superior to PCI by significantly reducing rates of death and myocardial infarction. ${ }^{10}$ Diabetes, however, was not a useful variable in the SSII, despite medically treated diabetes being stratified at randomization in the SYNTAX trial and reported in $26 \%$ of patients. Numerous arguments might explain this apparent divergence. First, diabetes was not an independent predictor of mortality in the SYNTAX trial. ${ }^{35}$ Second, diabetes did not have an interaction effect $(\mathrm{P}=0.67)$ with $\mathrm{CABG}$ or $\mathrm{PCI}$ for longterm mortality. ${ }^{14}$ Diabetes is a systemic disease, the severity and duration of which have a specific effect on organs such as the heart (detected on complex coronary anatomy and LVEF); peripheral vascular disease (a sign of systemic atherosclerosis); kidney (detected on creatinine clearance); and age (older patients are representative of a longer diabetes multi-organ effect). These arguments may be exemplified by a large population-based cohort study and meta-analysis involving 128,505 individuals with diabetes in which patients without diabetes but with chronic kidney disease and proteinuria had a stronger as- 
sociation with risk of myocardial infarction, and a higher rate of mortality, compared with those with diabetes. ${ }^{36}$

Finally, it must be acknowledged that no risk-scoring system is perfect and that careful multidisciplinary clinical reasoning remains vital for decision-making. ${ }^{11}$ SSII, however, can be a useful instrument in this process.

\section{Study Limitations}

This study has the inherent limitations of a retrospective analysis. The ultimate goal of SSII is to assist the heart team in the decision-making process between CABG and PCI. ${ }^{37}$ Thus, a prospective study would be needed to achieve true validation of SSII, where the decision between CABG and PCI is randomized. The present analysis, being retrospective, cannot assess the treatment recommendation based on SSII for the simple fact that the decision was likely made based on a combination of measured variables (as included in SSII) and unmeasured variables (eg, bleeding risk, duration of dual antiplatelet therapy, frailty etc). Presently, validation of SSII is a pre-specified endpoint in the ongoing randomized EXCEL trial (NCT01205776), and SYNTAX trial II, which will use SSII to recruit participants based on patient safety. In the latest trial, functional lesion assessment was added to improve late PCI outcomes and it is plausible that this approach may improve the discrimination of anatomical SS. ${ }^{38}$

In the PCI cohort of the CREDO-Kyoto registry patients were treated mainly with first-generation drug-eluting stent (DES). It is possible that its performance will be affected by the use of newer generation DES. SSII, however, focuses on 4-year overall mortality, an outcome that, apparently, is not affected by the type of stent used. For instance, in a recent meta-analysis of 20 clinical trials that included 20,005 patients, stent type did not alter the overall mortality, unlike late-lumen loss and stent thrombosis rate. ${ }^{39}$ Therefore, we do not expect that the type of DES prescribed will affect the predictions made by the PCI model of SSII.

\section{Conclusions}

SSII has robust prognostic accuracy, both in CABG and PCI patient groups and - compared with the anatomical SS alone - was able to stratify patients for late mortality in a real-world complex CAD Eastern population.

\section{Acknowledgments}

H.M.G.-G. and M.-A.M. are employees of Cardialysis (an academic Clinical Research Organization). The other authors report no conflicts of interest.

\section{References}

1. Smith SC Jr, Feldman TE, Hirshfeld JW Jr, Jacobs AK, Kern MJ, King SB 3rd, et al. ACC/AHA/SCAI 2005 guideline update for percutaneous coronary intervention - summary article: A report of the American College of Cardiology/American Heart Association Task Force on Practice Guidelines (ACC/AHA/SCAI Writing Committee to update the 2001 guidelines for percutaneous coronary intervention). Circulation 2006; 113: 156-175.

2. Kushner FG, Hand M, Smith SC Jr, King SB 3rd, Anderson JL, Antman EM, et al. 2009 focused updates: ACC/AHA guidelines for the management of patients with ST-elevation myocardial infarction (updating the 2004 guideline and 2007 focused update) and ACC/ AHA/SCAI guidelines on percutaneous coronary intervention (updating the 2005 guideline and 2007 focused update): A report of the American College of Cardiology Foundation/American Heart Association Task Force on Practice Guidelines. J Am Coll Cardiol 2009; 54: 2205-2241.

3. Iqbal J, Gunn J, Serruys PW. Coronary stents: Historical development, current status and future directions. Br Med Bull 2013; 106:
$193-211$.

4. Henderson RA, Pocock SJ, Sharp SJ, Nanchahal K, Sculpher MJ, Buxton MJ, et al. Long-term results of RITA-1 trial: Clinical and cost comparisons of coronary angioplasty and coronary-artery bypass grafting. Randomised Intervention Treatment of Angina. Lancet 1998; 352: $1419-1425$.

5. Rodriguez A, Mele E, Peyregne E, Bullon F, Perez-Balino N, Liprandi MI, et al. Three-year follow-up of the Argentine randomized trial of percutaneous transluminal coronary angioplasty versus coronary artery bypass surgery in multivessel disease (ERACI). J Am Coll Cardiol 1996; 27: 1178-1184.

6. Hueb WA, Soares PR, Almeida De Oliveira S, Arie S, Cardoso RH, Wajsbrot DB, et al. Five-year follow-up of the Medicine, Angioplasty, or Surgery Study (MASS): A prospective, randomized trial of medical therapy, balloon angioplasty, or bypass surgery for single proximal left anterior descending coronary artery stenosis. Circulation 1999; 100: II107-II113.

7. Five-year clinical and functional outcome comparing bypass surgery and angioplasty in patients with multivessel coronary disease: A multicenter randomized trial: Writing group for the Bypass Angioplasty Revascularization Investigation (BARI) investigators. JAMA 1997; 277: 715-721.

8. Serruys PW, Ong AT, van Herwerden LA, Sousa JE, Jatene A, Bonnier JJ, et al. Five-year outcomes after coronary stenting versus bypass surgery for the treatment of multivessel disease: The final analysis of the Arterial Revascularization Therapies Study (ARTS) randomized trial. J Am Coll Cardiol 2005; 46: 575-581.

9. Mohr FW, Morice MC, Kappetein AP, Feldman TE, Stahle E, Colombo A, et al. Coronary artery bypass graft surgery versus percutaneous coronary intervention in patients with three-vessel disease and left main coronary disease: 5-year follow-up of the randomised, clinical SYNTAX trial. Lancet 2013; 381: 629-638.

10. Farkouh ME, Domanski M, Sleeper LA, Siami FS, Dangas G, Mack MS, et al. Strategies for multivessel revascularization in patients with diabetes. $N$ Engl J Med 2012; 367: 2375-2384.

11. Iqbal J, Serruys PW, Taggart DP. Optimal revascularization for complex coronary artery disease. Nat Rev Cardiol 2013; 10: 635647.

12. Wijns W, Kolh P, Danchin N, Di Mario C, Falk V, Folliguet T, et al. Guidelines on myocardial revascularization. Eur Heart J 2010; 31: $2501-2555$.

13. Fihn SD, Gardin JM, Abrams J, Berra K, Blankenship JC, Dallas AP, et al. 2012 ACCF/AHA/ACP/AATS/PCNA/SCAI/STS guideline for the diagnosis and management of patients with stable ischemic heart disease: A report of the American College of Cardiology Foundation/ American Heart Association Task Force on Practice Guidelines, and the American College of Physicians, American Association for Thoracic Surgery, Preventive Cardiovascular Nurses Association, Society for Cardiovascular Angiography and Interventions, and Society of Thoracic Surgeons. J Am Coll Cardiol 2012; 60: e44-e164, doi:10.1016/j.jacc.2012.07.013.

14. Farooq V, van Klaveren D, Steyerberg EW, Meliga E, Vergouwe Y, Chieffo A, et al. Anatomical and clinical characteristics to guide decision making between coronary artery bypass surgery and percutaneous coronary intervention for individual patients: Development and validation of SYNTAX score II. Lancet 2013; 381: 639-650.

15. Chieffo A, Meliga E, Latib A, Park SJ, Onuma Y, Capranzano P, et al. Drug-eluting stent for left main coronary artery disease. The DELTA registry: A multicenter registry evaluating percutaneous coronary intervention versus coronary artery bypass grafting for left main treatment. JACC Cardiovasc Interv 2012; 5: 718-727.

16. Serruys PW, Farooq V, Vranckx P, Girasis C, Brugaletta S, GarciaGarcia HM, et al. A global risk approach to identify patients with left main or 3-vessel disease who could safely and efficaciously be treated with percutaneous coronary intervention: The SYNTAX trial at 3 years. JACC Cardiovasc Interv 2012; 5: 606-617.

17. Kimura T, Morimoto T, Furukawa Y, Nakagawa Y, Kadota K, Iwabuchi M, et al. Long-term safety and efficacy of sirolimus-eluting stents versus bare-metal stents in real world clinical practice in Japan. Cardiovasc Interv Ther 2011; 26: 234-245.

18. Harrell FE Jr, Califf RM, Pryor DB, Lee KL, Rosati RA. Evaluating the yield of medical tests. JAMA 1982; 247: 2543-2546.

19. Kappetein AP, Feldman TE, Mack MJ, Morice MC, Holmes DR, Stahle E, et al. Comparison of coronary bypass surgery with drugeluting stenting for the treatment of left main and/or three-vessel disease: 3-year follow-up of the SYNTAX trial. Eur Heart J 2011; 32: $2125-2134$.

20. Pencina MJ, D'Agostino RB Sr, D’Agostino RB Jr, Vasan RS. Evaluating the added predictive ability of a new marker: From area under the ROC curve to reclassification and beyond. Stat Med 2008; 27: 
157-172; discussion 207-212.

21. Steyerberg EW, Pencina MJ. Reclassification calculations for persons with incomplete follow-up. Ann Intern Med 2010; 152: 195-196; author reply 196-197.

22. Shiomi H, Tamura T, Niki S, Tada T, Tazaki J, Toma M, et al. Interand intra-observer variability for assessment of the synergy between percutaneous coronary intervention with TAXUS and cardiac surgery (SYNTAX) score and association of the SYNTAX score with clinical outcome in patients undergoing unprotected left main stenting in the real world. Circ J 2011; 75: 1130-1137.

23. Anderson RP. First publications from the Society of Thoracic Surgeons national database. Ann Thorac Surg 1994; 57: 6-7.

24. Ad N, Barnett SD, Speir AM. The performance of the EuroSCORE and the Society of Thoracic Surgeons mortality risk score: The gender factor. Interact Cardiovasc Thorac Surg 2007; 6: 192-195.

25. Handa N, Miyata H, Motomura N, Nishina T, Takamoto S. Procedure- and age-specific risk stratification of single aortic valve replacement in elderly patients based on Japan Adult Cardiovascular Surgery Database. Circ J 2012; 76: 356-364.

26. Park KW, Kang J, Kang SH, Ahn HS, Lee HY, Kang HJ, et al. Usefulness of the SYNTAX and clinical SYNTAX scores in predicting clinical outcome after unrestricted use of sirolimus- and everolimuseluting stents. Circ J 2013; 77: 2912-2921.

27. Capodanno D. Beyond the SYNTAX score: Advantages and limitations of other risk assessment systems in left main percutaneous coronary intervention. Circ J 2013; 77: 1131-1138.

28. Steyerberg EW, Vickers AJ, Cook NR, Gerds T, Gonen M, Obuchowski N, et al. Assessing the performance of prediction models: A framework for traditional and novel measures. Epidemiology 2010; 21: 128-138.

29. Ikeda N, Saito E, Kondo N, Inoue M, Ikeda S, Satoh T, et al. What has made the population of Japan healthy? Lancet 2011; 378: 1094-1105.

30. Sekikawa A, Satoh T, Hayakawa T, Ueshima H, Kuller LH. Coronary heart disease mortality among men aged $35-44$ years by prefecture in Japan in 1995-1999 compared with that among white men aged 35-44 by state in the United States in 1995-1998: Vital statistics data in recent birth cohort. Jpn Circ J 2001; 65: 887-892.

31. Rumana N, Kita Y, Turin TC, Murakami Y, Sugihara H, Morita Y, et al. Trend of increase in the incidence of acute myocardial infarction in a Japanese population: Takashima AMI Registry, 1990-2001. Am J Epidemiol 2008; 167: 1358-1364.

32. Sekikawa A, Willcox BJ, Usui T, Carr JJ, Barinas-Mitchell EJ,
Masaki KH, et al. Do differences in risk factors explain the lower rates of coronary heart disease in Japanese versus U.S. women? $J$ Womens Health (Larchmt) 2013; 22: 966-977.

33. Kohsaka S, Kimura T, Goto M, Lee VV, Elayda M, Furukawa Y, et al. Difference in patient profiles and outcomes in Japanese versus American patients undergoing coronary revascularization (collaborative study by CREDO-Kyoto and the Texas Heart Institute Research Database). Am J Cardiol 2010; 105: 1698-1704.

34. Ishikawa T, Nakano Y, Endoh A, Kubota T, Suzuki T, Nakata K, et al. Significantly lower incidence of early definite stent thrombosis of drug-eluting stents after unrestricted use in Japan using ticlopidine compared to western countries using clopidogrel: A retrospective comparison with western mega-studies. J Cardiol 2009; 54: 238-244.

35. Farooq V, Serruys PW, Bourantas C, Vranckx P, Diletti R, Garcia Garcia HM, et al. Incidence and multivariable correlates of long-term mortality in patients treated with surgical or percutaneous revascularization in the synergy between percutaneous coronary intervention with taxus and cardiac surgery (SYNTAX) trial. Eur Heart J 2012; 33: $3105-3113$.

36. Tonelli M, Muntner P, Lloyd A, Manns BJ, Klarenbach S, Pannu N, et al. Risk of coronary events in people with chronic kidney disease compared with those with diabetes: A population-level cohort study. Lancet 2012; 380: 807-814.

37. Farooq V, van Klaveren D, Steyerberg EW, Serruys PW. SYNTAX score II: Authors' reply. Lancet 2013; 381: 1899-1900.

38. Tanaka H, Chikamori T, Hida S, Igarashi Y, Shiba C, Usui Y, et al. Relationship of SYNTAX score to myocardial ischemia as assessed on myocardial perfusion imaging. Circ J 2013; 77: 2772-2777.

39. Lupi A, Gabrio Secco G, Rognoni A, Lazzero M, Fattori R, Sheiban I, et al. Meta-analysis of bioabsorbable versus durable polymer drugeluting stents in 20,005 patients with coronary artery disease: An update. Catheter Cardiovasc Interv 2014; 83: E193-E206, doi:10.1002/ ccd.25416.

\section{Supplementary Files}

Supplementary File 1

Table S1. Reclassification table: 4-year risk strata for PCI vs. CABG

Please find supplementary file(s);

http://dx.doi.org/10.1253/circj.CJ-14-0204 